\title{
Local Intelligence for Remote Surveillance and Control of Flow in Fluid Transportation System
}

Thangavel Subramaniam, Priyanka Bhaskaran*

Department of Mechatronics Engineering, Kongu Rngineering College, Perundurai (638060), Erode, India

Corresponding Author Email: priyankabhaskaran1993@ gmail.com

https://doi.org/10.18280.ama_c.740102

Received: 10 November 2018

Accepted: 2 March 2019

\section{Keywords:}

local intelligent, IMC based PID controller, remote monitoring \& control, pressure \& flow rate

\begin{abstract}
In order to enhance the proprietary of remote monitoring and control technology, this paper emphasizes the development of IoT based architecture with local intelligent using IMC based PID controller can be integrated with SCADA and this research work spectacle only the development and application of Local Intelligence present in the proposed IoT architecture for remote monitoring and control of concerned field parameters. This proposed local intelligence tactic governs the input and output from a hardware platform positioned on a process plant, organize added processing power for meticulous analysis in the control center by the use of software integration, data acquisition and logging on a created hybrid database, and spectacle significant processed post-data statistics to operators via a standard SCADA. The established local intelligence is experimentally validated in the lab scale experimental fluid transport system to monitor and control pressure and flow rate parameters remotely by incorporating with CENTUM CS 3000. The simulation and experimental results of Local Intelligence using an IMC-PID controller on a lab scale fluid transport system are conveyed with its numerical data.
\end{abstract}

\section{INTRODUCTION}

This paper emphasizes an internet of things (IoT) based reliable monitoring and control with local intelligence using IMC-PID controller modular architecture design along with SCADA. This architecture with local intelligence using IMCPID controller facilitates minimum human intervention will provide better workplace safety, maintenance of assets and will perform predictive maintenance of various industrial assets by analyzing various parameters (sensed data) and detecting failure modes either before they are going to take place or when the equipment will likely to fail or need service [1-4]. This paper enlightens the brief information on the development of Local Intelligence using an IMC-PID controller which is present in the proposed IoT architecture.

\section{LAB SCALE EXPERIMENTAL SETUP OF FLUID TRANSPORT SYSTEM}

The lab scale experimental fluid transport system consists of the pumping unit, the transmitting pipes having a diameter of 1 inch about $15 \mathrm{~m}$ long for the well-organized and extended transmission and manifold analog sensors at different distinctive locations with its corresponding control valves installed to compensate its drops/loss during the fluid transportation in the pipelines. The block diagram with proposed IoT architecture with local intelligence for the lab scale investigational setup envisaging the physical categorizations of apparatus positioned and also exhibits all the piping with directional tracks and equipment's facts with their controls is shown in Figure 1.

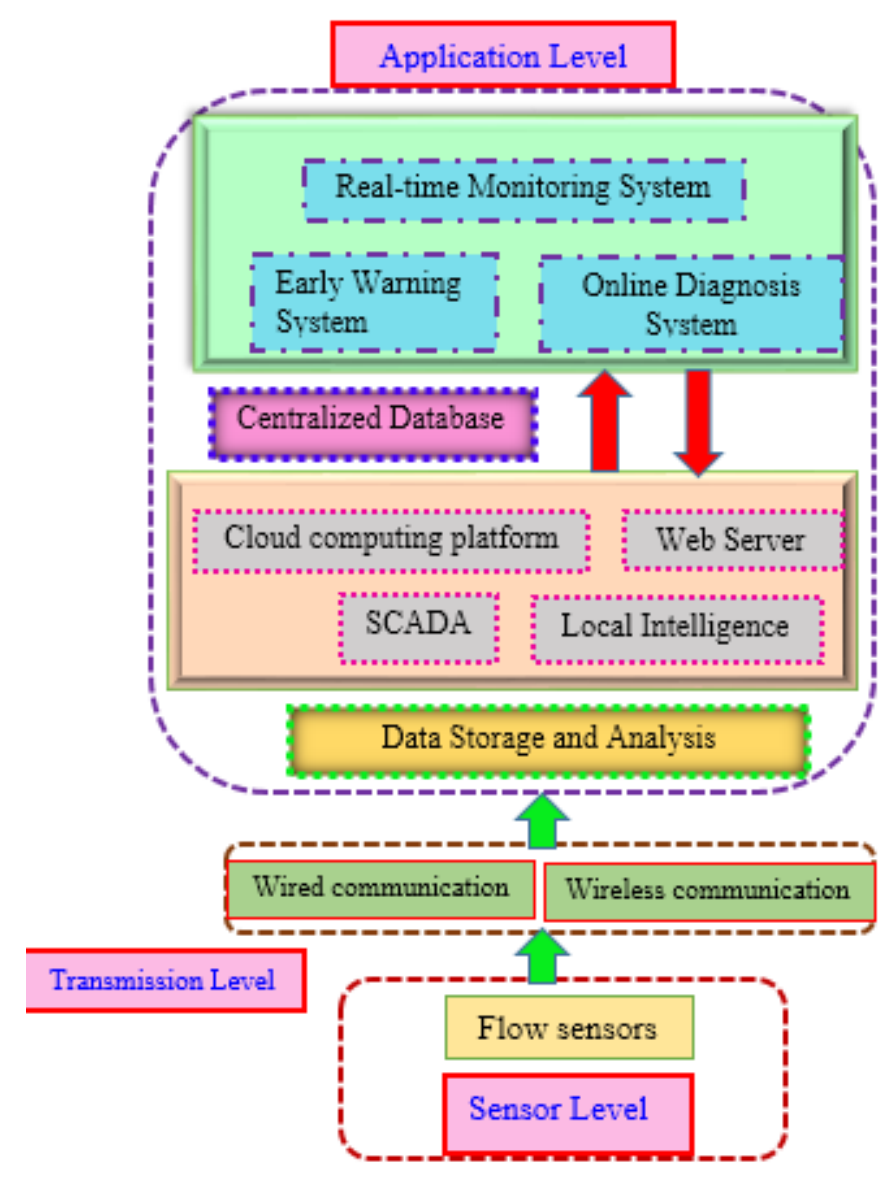

Figure 1. IoT based architecture with local intelligence for the process plant 
When the process plant is on track to run, initially reservoir tank fills up to $20 \%$ of its capacity, and then the electric pump is actuated to suck the fluid from the tank in order to transmit the fluid to each section. When the fluid starts to pass through the pipelines its corresponding pressure and flow transmitter send its present pressure and flow rate data to the $\mathrm{I} / \mathrm{O}$ hub module station $[5,6]$. During transportation to regulate the pressure and flow rate of the transmitting fluid, the opening and closing of the control valves are operated by the $\mathrm{I} / \mathrm{P}$ converter in order to maintain its preferred effective range limits until the destination of the long run, till it drains from the process tank as shown in Figure 2.

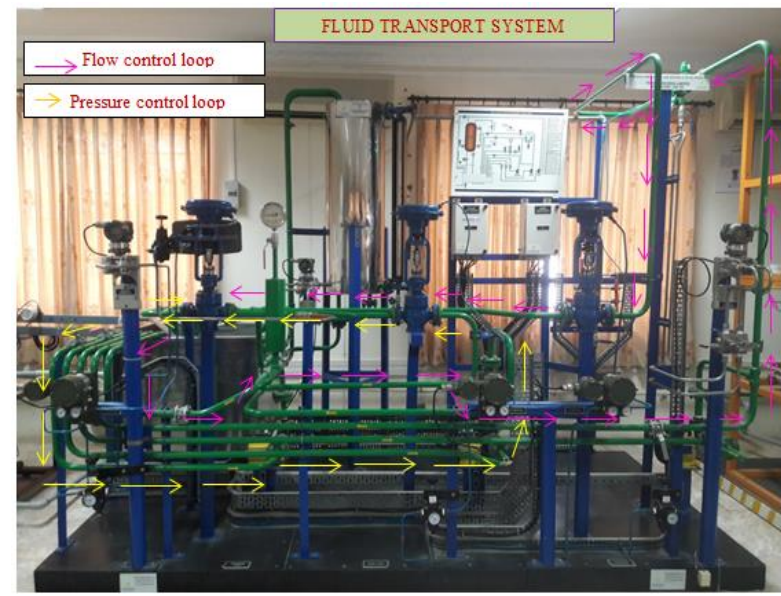

Figure 2. The lab scale experimental setup of the fluid transport system

\section{FUNCTIONAL DEPLOYMENT OF SCADA FRAME WORK}

The SCADA incorporating local intelligence using an IMCPID controller is developed for the experimental setup of the fluid transport system is shown in Figure 3 to deal with remote surveillance and control of flow and pressure and it also encompasses of individual interface displays for flow rate and its respective pressure parameters of the fluid.

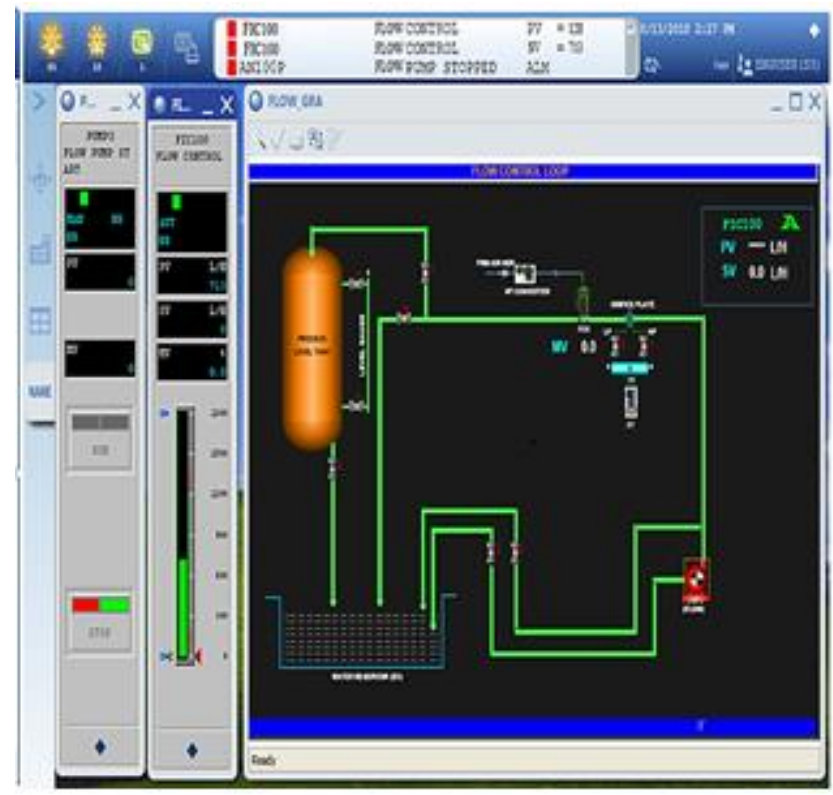

Figure 3. Individual SCADA view of flow control loop
The developed SCADA provides more functional utility options like system message banner, graphic view with graphics and control attributes, trend view, browser bar and tuning window.

\section{SYSTEM MODELING FOR FLOW CONTROL LOOP}

For modeling the fluid transport system, a transient response curve is chronicled by modifying the control valve opening in order to acquire the equivalent liquid pressure and flow rate changes on the pipeline in the open loop structure. This open loop experimentation reveals pressure of the liquid is at a maximum rate and the flow is at a minimum value when the opening of the control valve is around $10 \%$ of the overall opening and vice versa when the control valve opening reaches its full stretch of $100 \%$. The open loop test run is carried out by linearly adjusting the percentage of control valve opening. The experimental analysis call-ups with the initial flow rate of $179 \mathrm{lph}$ and pressure of $2.2 \mathrm{~kg} / \mathrm{cm}^{2}$ and unremitting readings were documented until the flow rate and pressure influences a balanced/fixed state. Open loop readings were noted for the percentage of control valve opening versus flow rate and pressure through Centum CS 3000 as displayed in Figure 4 and by which the first order model considerations (process gain $\mathrm{K}_{\mathrm{p}}$ and process time constant $\tau_{\mathrm{P}}$ ) are calculated.

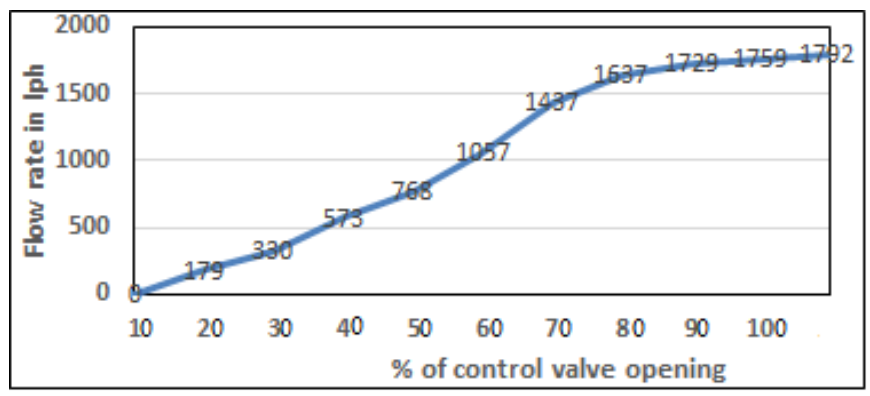

Figure 4. Flow rates of the liquid for the different level of control valve opening

The identified FOPTD model for the flow control loop in the process plant is represented as,

$$
\mathrm{G}(\mathrm{s})=\frac{0.914}{8.317 \mathrm{~s}+1} e^{-5.16 \mathrm{~s}}
$$

The system model identification is arrived by formulated the real-time experimental data obtained from the fluid transport system in open loop performance analysis on process plant $[7,8]$.

\section{ROBUST CONTROLLER DESIGN}

The PID (proportional-integral-derivative) controller serves as one of the popular and extensively applied controllers in the industrial sector due to its uncomplicatedness, robustness and affords wide applicability to near-optimal enactment. Even though innovative control techniques can deliver substantial improvements, an elegant-characterized PID controller has ascertained to be suitable for an enormous quantity of engineering control loops [9]. 


\subsection{Ziegler-Nicholas PID (ZN-PID) controller}

The Ziegler-Nichols PID (ZN-PID) Controller is the utmost universally employed the heuristic technique of fine-tuning a PID controller in all the engineering-oriented feedback control application. The ability to predict the future errors in the process is possible in the PID controller, meanwhile, it can eliminate oscillations and can decrease the rise time in the performance [10].

Table 1. ZN-PID controller tuning parameters with values

\begin{tabular}{|l|l|l|l|l|l|}
\hline \multirow{2}{*}{ Tuning Rules } & \multicolumn{5}{|c|}{ Tuning Parameters for flow rate } \\
\cline { 2 - 6 } & $\mathbf{k}_{\mathbf{c}}$ & $\tau_{\mathbf{i}}(\mathbf{s})$ & $\tau_{\mathbf{d}}(\mathbf{s})$ & $\mathbf{k}_{\mathbf{i}}$ & $\mathbf{k}_{\mathbf{d}}$ \\
\hline $\begin{array}{l}\mathrm{Kc}=\frac{\mathrm{a} \tau \mathrm{p}}{\theta \mathrm{Kp}} ; \mathrm{a} \in[1.2,2] \\
\tau \mathrm{i}=2 \theta \text { and } \tau \mathrm{d}=0.5 \theta\end{array}$ & 1.84 & 3.77 & 1.42 & 0.49 & 2.62 \\
\hline
\end{tabular}

where $\mathrm{k}_{\mathrm{c}}$ is controller gain and $\tau_{\mathrm{i}}, \tau_{\mathrm{d}}$ indicates the integral and derivative gain.

\subsection{IMC-PID controller design for fluid transport process plant}

The design of the IMC control [11] feedback structure for fluid transport system is carried out by assigning $G_{p}$ is the process, $\widetilde{G_{p}}$ the process model, q the IMC controller, $f_{r}$ the set-point filter, and $G_{c}$ the equivalent feedback controller. For the nominal case (i.e., $G_{p}=\widetilde{G_{p}}$ ), the set-point and disturbance responses in the IMC control can be simplified as:

$$
Y=G_{p} q f_{r}+\left(1-G_{p} q\right) G_{p} d
$$

According to the IMC parameterization [1], the process model $\widetilde{G_{p}}$ is factored into two parts:

$$
\widetilde{G_{p}}=P_{m} P_{A}
$$

where $\mathrm{P}_{m}$ is the portion of the model inverted by the controller, $\mathrm{P}_{A}$ is the portion of the model not inverted by the controller and $\mathrm{p} A(0)=1$. Since the IMC controller $\mathrm{q}$ is designed as $q=$ $P_{m}{ }^{-1} f$, the first condition is satisfied automatically. The second condition can be fulfilled by designing the IMC filter (f) as

$$
f=\frac{\sum_{i=1}^{m} \alpha_{i} s^{i}}{\left(\tau_{c} s+1\right)^{r}}
$$

where $\tau c$ is an adjustable parameter which controls the tradeoff between the performance and robustness; $r$ is selected to be large enough to make the IMC controller (semi-)proper; $\alpha i$ are determined by Eq. (8) to cancel the poles near zero in $G_{p}$.

$$
1-\left.G_{P} q\right|_{s=\mathrm{z} 1, \mathrm{z} 2, \ldots, \mathrm{z} m}=\left|1-\frac{P_{A}\left(\sum_{i=1}^{m} \alpha_{i} s^{i}\right)}{\left(\tau_{c} s+1\right)^{r}}\right|_{s=\mathrm{z} 1, \mathrm{z} 2, \ldots, \mathrm{z} m}=0
$$

Thus, the resulting set-point and disturbance responses are obtained as

$$
\frac{y}{d}=\left(1-G_{P} q\right) G_{P}=\left(1-\frac{P_{A}\left(\sum_{i=1}^{m} \alpha_{i} s^{i}\right)}{\left(\tau_{c} s+1\right)^{r}}\right) G_{P}
$$

The numerator expression $\sum_{i=1}^{m} a_{i} s^{i}+1$ in Eq. (6) causes sometimes an excessive overshoot in the servo response, which can be eliminated by introducing the set-point filter f $r$ to compensate for the overshoot in the servo response. The ideal feedback controller that is equivalent to the IMC controller [12] can be expressed in terms of the internal model $\widetilde{G_{p}}$ and the IMC controller q:

$$
\mathrm{G}_{\mathrm{C}}=\frac{\mathrm{q}}{1-\mathrm{G}_{\mathrm{p}} \mathrm{q}}=\frac{\mathrm{P}_{\mathrm{m}}{ }^{-1} \frac{\sum_{\mathrm{i}=1}^{\mathrm{m}} \alpha_{\mathrm{i}} \mathrm{s}^{\mathrm{i}}}{\left(\tau_{\mathrm{c}} \mathrm{s}+1\right)^{\mathrm{r}}}}{1-\frac{\mathrm{P}_{\mathrm{A}}\left(\sum_{\mathrm{i}=1}^{\mathrm{m}} \alpha_{\mathrm{i}} \mathrm{s}^{\mathrm{s}}\right)}{\left(\tau_{\mathrm{C}} \mathrm{s}+1\right)^{\mathrm{r}}}}
$$

The resulting controller in Eq. (7) is physically realizable, but it does not have the standard PI/PID form. The desired form of the controller can be obtained by using the approximation of the dead time term in the process. In this work, both simplicity and approximation error due to the dead time term has been considered carefully during the PI/PID controller design. First order plus dead time (FOPDT) process is a representative model commonly used in the chemical process industries. On the basis of the above design principle, the FOPDT process has been considered as

$$
\mathrm{G}(\mathrm{s})=\frac{\mathrm{Kp}}{\tau \mathrm{pS}+1} e^{-\theta \mathrm{s}}
$$

where $K_{p}=$ process gain, $\tau_{P}=$ time constant and $\theta=$ process delay, the IMC filter selected is $\mathrm{f}=\frac{\alpha s+1}{\left(\tau_{c} s+1\right)^{2}}$. The ideal feedback controller, Gc, equivalent to the IMC controller [9, 11], can be obtained after the approximation of the dead time by Taylor series expansion combining with equation 7 with IMC filter results in

$$
G_{c}=\frac{(\alpha s+1)}{K\left(2 \tau_{c}-\alpha+\theta\right) s} \frac{(\tau s+1)}{\left[\frac{\left(\tau_{c}^{2}+\tau_{c} \theta\right)}{\left(2 \tau_{c}-\alpha+\theta\right)} s+1\right]}
$$

From Eq. (9), the resulting PID controller can be obtained after simplification as

$$
\mathrm{Kc}=\frac{\alpha}{K p(2 \tau \mathrm{i}-\alpha+\theta)} \tau_{\mathrm{i}}=\alpha ; \tau_{\mathrm{d}}=\tau_{2}
$$

where $\mathrm{K} c$ is controller gain, $\tau_{i}$ is integral time and $\tau_{d}$ is derivative time. The value of $\alpha$ (non-minimum phase element) is selected so that it cancels out the pole at $s=-1 / \tau$ and the value of $\alpha$ is obtained as

$$
\alpha=\tau\left\{1-\left(1-\frac{\tau c}{\tau}\right)^{2} e^{-\frac{\theta}{\tau}} ; \tau_{\mathrm{c}}=2 \theta\right.
$$

By using this tuning, it is possible to get the enhanced disturbance rejection performance by adjusting the single tuning parameter of the controller. The important feature of this controller is that it deals with the nonlinear and stable process in a unified way. The parameters of the IMC-PID controller are shown in Table 2.

Table 2. IMC-PID controller parameters

\begin{tabular}{|c|c|c|c|c|c|}
\hline \multirow{2}{*}{ Controller } & \multicolumn{5}{|c|}{ Tuning Parameters for flow rate } \\
\cline { 2 - 6 } & $\mathbf{k}_{\mathbf{c}}$ & $\tau_{\mathbf{i}}(\mathbf{s})$ & $\tau_{\mathbf{d}}(\mathbf{s})$ & $\mathbf{k}_{\mathbf{i}}$ & $\mathbf{k}_{\mathbf{d}}$ \\
\hline IMC-PID & 1.89 & 3.46 & 2.37 & 0.54 & 4.5 \\
\hline
\end{tabular}

\subsection{Cohen-coon PID (CC-PID) controller}

The Cohen-coon tuning system is the more difficult and 
complex form of open loop Ziegler Nicholas method and its tuning parameter relations were established empirically to afford closed loop reaction for a feedback system which sustains $1 / 4$ decay ratio.

The tuning parameters relations are given and their corresponding controller parameter of CC-PID [5] is presented in Table 3.

$$
K c=\frac{1}{K_{p}} \cdot \frac{\mathrm{T} \mathbf{p}}{\theta}\left(\frac{4}{3}+\frac{\theta}{4 \mathrm{~T} \mathbf{p}}\right) ; \tau_{i}=d \frac{32+6 \theta / \mathrm{Tp}}{13+8 \theta / \mathrm{T} \mathbf{p}} ; \tau_{d}=d \frac{4}{11+2 \theta / \mathrm{Tp}}
$$

Table 3. CC-PID controller parameters

\begin{tabular}{|l|c|c|c|c|c|}
\hline \multirow{2}{*}{ Controller } & \multicolumn{5}{|c|}{ Tuning Parameters for flow rate } \\
\cline { 2 - 6 } & $\mathbf{k}_{\mathbf{c}}$ & $\tau_{\mathbf{i}}(\mathbf{s})$ & $\tau_{\mathbf{d}}(\mathbf{s})$ & $\mathbf{k}_{\mathbf{I}}$ & $\mathbf{k}_{\mathbf{D}}$ \\
\hline Cohen-Coon & 1.28 & 5.14 & 0.69 & 0.25 & 0.9 \\
\hline
\end{tabular}

\section{RESULTS AND DISCUSSION}

The simulation and real-time investigational work have been conceded on the flow and pressure control loop outfit to examine the performance of the ZN tuned PID, CC-PID and IMC tuned PID controllers. To contrivance the closed loop control purpose, a PID block is established in the CENTUM CS 3000 in which feedback regulating signal is programmed to pass through the control valve to form closed loop feedback structure in fluid transport process plant.

\subsection{Simulation results}

In the simulation work, the recitations of different controllers are equated by setting the peak of maximum uncertainty $\left(\mathrm{M}_{\mathrm{s}}\right)$ value for comparison. It is noteworthy to ensure IAE, TV and $\mathrm{M}_{\mathrm{s}}$ (Integral Absolute Error, Total Variation of the input, uncertainty margin value) to be lesser, but for a best characterized tuned controller causes the existence of trade-off, which indicates a declination in IAE infers an escalation in TV and $\mathbf{M}_{\mathrm{s}}$ (and vice versa). The controller structure of the PID block for the fluid transportation system to monitor pressure and flow rate is developed using SIMULINK in MATLAB platform is presented in Figure 5.

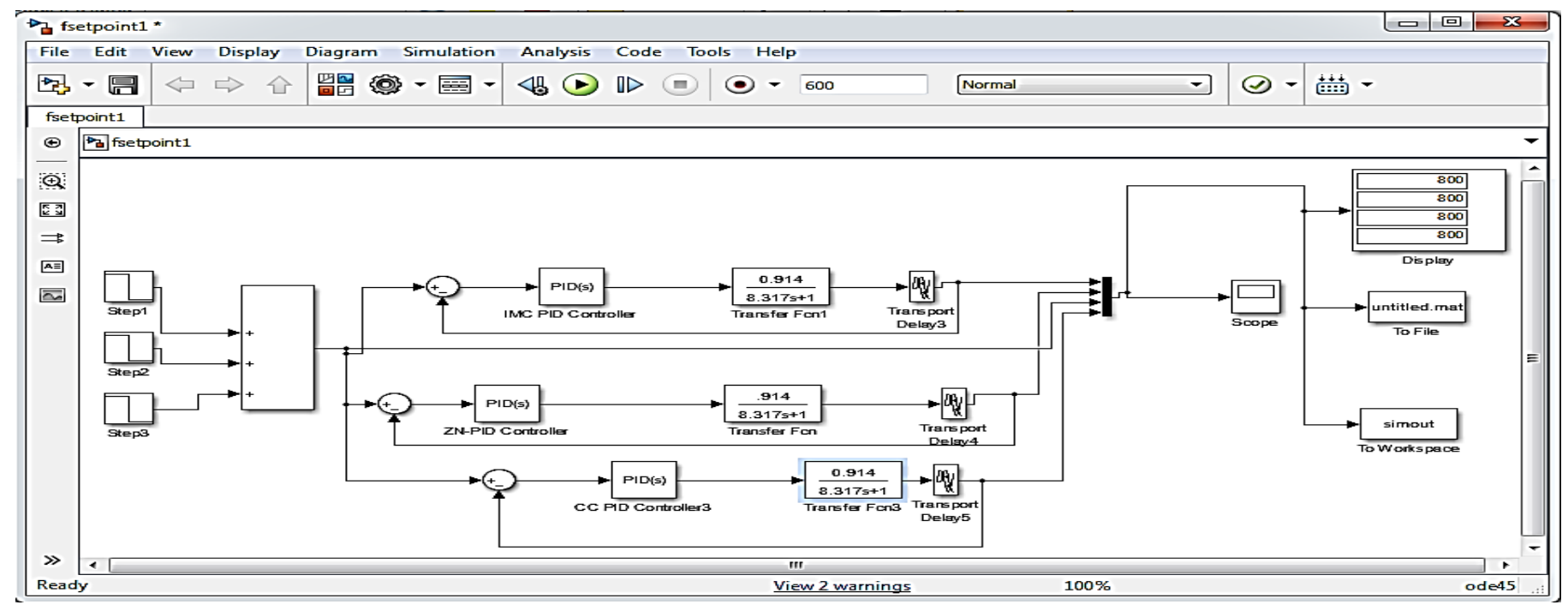

Figure 5. MATLAB platform based created Simulink model for flow control loop

6.1.1 Performance analyses for pressure and flow control loop of process plant

The performance of $\mathrm{ZN}, \mathrm{CC}$ and IMC-PID controller are investigated at required setpoint ranges in order to normalize both pressure and flow rate of the fluid being transmitted. The closed-loop simulated transient responses for flow rates at the operational choice of $500 \mathrm{lph}$ for the time interval of $t=0-50$ $\mathrm{s}$ are unveiled on Figure 6.

From the Figure 6, it is clear that the IMC-PID controller is enforced to trail the fixed operating point of flow rate at short duration of time of about 39 seconds and maintain the steady state with overshoot as compared to ZN-PID and CC-PID control techniques which settle at about 57 seconds and 62.5 seconds for flow rate. It confirms that IMC-PID controller offers $9.39 \%$ of improved quality indices on comparing with $\mathrm{ZN}$ tuned PID and CC-PID controllers. The presence of overshoot in the IMC-PID controller performance ensures high rise time with quickly settling on its desired set point in order to improve the experimented operating condition of the fluid transport system.

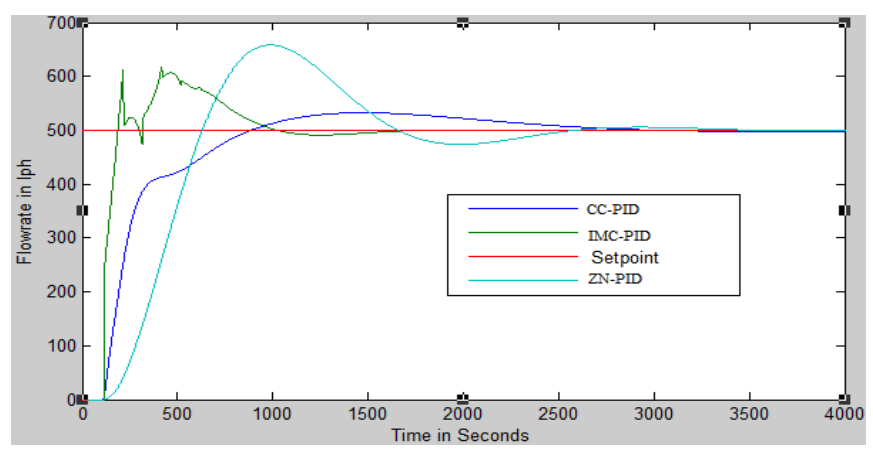

Figure 6. Performance analyses of ZN tuned PID, CC tuned PID, and IMC tuned PID controllers for flow control loop at a set point of $500 \mathrm{lph}$

6.1.2 Set point tracking for pressure and flow control loop

Closed loop simulated transient responses attained at different operating points such as 900 and $1400 \mathrm{lph}$ for the flow rate to confirm the robustness of the IMC-PID controller are shown in Figure 7. The Table 4 reveal that the performance 
of IMC-PID on comparing with ZN tuned PID and CC tuned PID controllers affords superior performance with the similar settings for altered operating points. Among the controller tuning rules, IMC-PID sustains the trepidations in the model parameters and pay for the extremely reliable and robust response when the operating point diverges. Figure 7 also ensures that IMC-PID controller endows the least possible error indices of $8.17 \%$ as compared with ZN tuned PID and CC-PID controllers. This pragmatic IMC-PID controller confirms the boosted performance meanwhile it has the talent to trajectory on faults online.

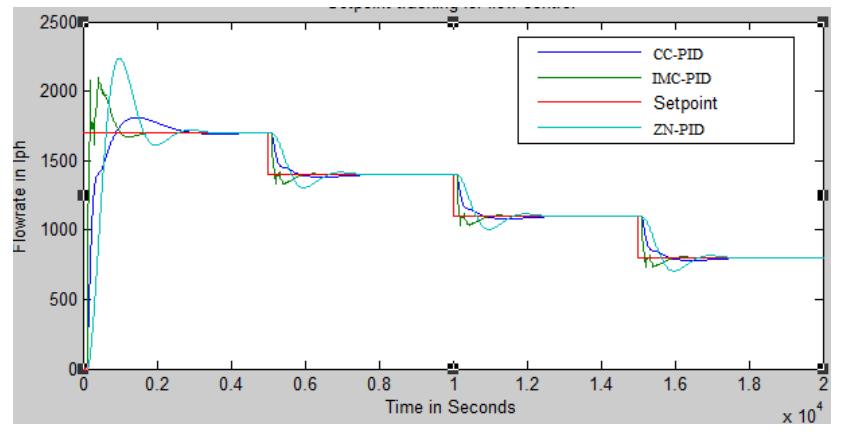

Figure 7. Performance analyses of $\mathrm{ZN}$ tuned PID, CC tuned PID, and IMC tuned PID controllers for flow control loop at different setpoint tracking

Table 4. Flow rate-Performance measures of the controllers at different operating points

\begin{tabular}{|c|c|c|c|c|}
\hline $\begin{array}{l}\text { Operating } \\
\text { points } \\
\text { in lph }\end{array}$ & $\begin{array}{c}\text { Error and } \\
\text { Quality } \\
\text { Indices } \\
\text { Measures }\end{array}$ & $\begin{array}{c}\text { IMC- } \\
\text { PID }\end{array}$ & $\begin{array}{l}\text { CC- } \\
\text { PID }\end{array}$ & $\begin{array}{l}\text { ZN- } \\
\text { PID }\end{array}$ \\
\hline \multirow{6}{*}{500} & ISE & 0.17 & 0.44 & 0.35 \\
\hline & IAE & 0.718 & 0.021 & 0.51 \\
\hline & ITAE & 0.912 & 0.39 & 0.324 \\
\hline & $\mathrm{t}_{\mathrm{r}}(\mathrm{Sec})$ & 2.1 & 6.3 & 8.99 \\
\hline & $\mathrm{t}_{\mathrm{s}}(\mathrm{Sec})$ & 17 & 26.5 & 34 \\
\hline & $\% \mathrm{M}_{\mathrm{p}}$ & 15.36 & 3.07 & 22.98 \\
\hline \multirow{6}{*}{900} & ISE & 0.67 & 0.76 & 0.41 \\
\hline & IAE & 0.36 & 0.43 & 0.901 \\
\hline & ITAE & 0.075 & 0.249 & 0.684 \\
\hline & $\mathrm{t}_{\mathrm{r}}(\mathrm{Sec})$ & 2.3 & 6.41 & 9.14 \\
\hline & $\mathrm{t}_{\mathrm{s}}(\mathrm{Sec})$ & 17 & 27.01 & 35.102 \\
\hline & $\% \mathrm{M}_{\mathrm{p}}$ & 14.89 & 3.152 & 21.39 \\
\hline \multirow{6}{*}{1400} & ISE & 0.87 & 0.356 & 0.872 \\
\hline & IAE & 0.94 & 0.58 & 0.112 \\
\hline & ITAE & 0.54 & 0.30 & 0.897 \\
\hline & $\mathrm{t}_{\mathrm{r}}(\mathrm{Sec})$ & 2 & 5.98 & 8.93 \\
\hline & $\mathrm{t}_{\mathrm{s}}(\mathrm{Sec})$ & 16.5 & 26.12 & 34.89 \\
\hline & $\% \mathrm{M}_{\mathrm{p}}$ & 14.57 & 2.936 & 21.134 \\
\hline
\end{tabular}

6.1.3 Disturbance rejection test for pressure and flow control loop

The disturbance rejection performance is investigated at the operating point of flow rate at $1300 \mathrm{lph}$. A step disturbance is introduced into the process by way of increasing the flow rate to $1600 \mathrm{lph}$ after the time period of 100 and 150 seconds as shown in Figure 8. As of the analysis result endorses the merit by pointing only IMC-PID controller damp the disturbance in a smaller time period of 19 seconds with less undershoot of $9.97 \%$ as compared to the CC-PID and ZN-PID PID controllers on pressure control loop.

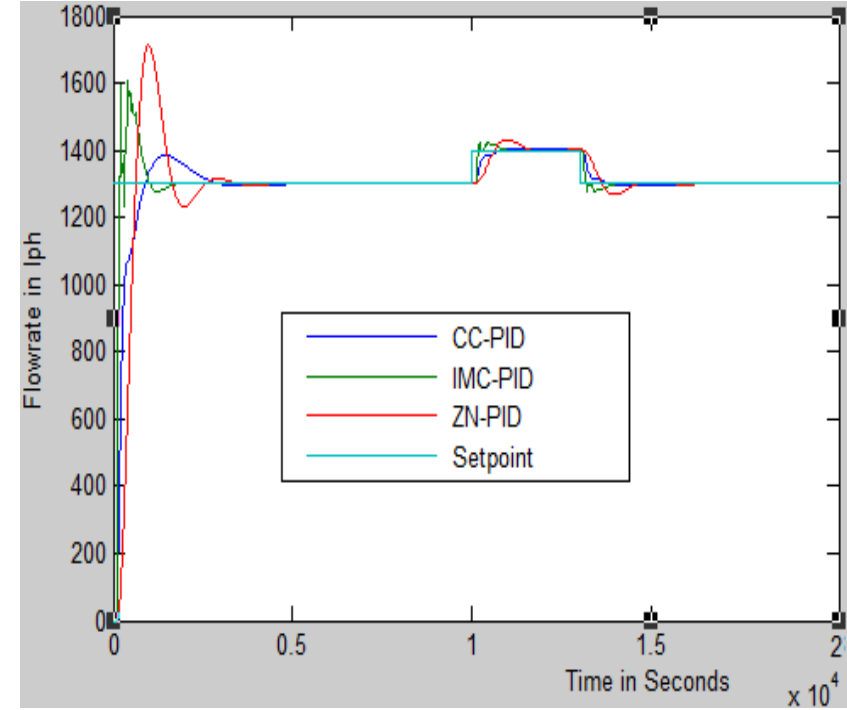

Figure 8. Performance analyses of $\mathrm{ZN}$ tuned PID, CC tuned PID, and IMC tuned PID controllers for flow control loop after a disturbance at a set point of $1300 \mathrm{lph}$

The application of IMC-PID controller on flow control loop divulges the sluggish disturbance rejection of $\mathrm{ZN}$ tuned PID and CC-PID controllers where IMC-PID tolerates the disruption with a short span of 31 seconds with enhanced quality indices. The error and quality indices of the output signal are applied to estimate the disturbance rejection presentation of the controllers for pressure and flow rates are given in Table 5.

Hence by simulation results, IMC-PID controller contributes optimal smallest settling time with least error integral value and highest robustness on comparing with $\mathrm{ZN}$ PID and CC-PID controllers and hence affords $12.97 \%$ enhanced performance in monitoring and regulating the pressure and flow rate variations through the control valve opening and closing to attain the preferred operating choice at the destination in the fluid transport system process plant.

Table 5. Performance measures after a disturbance at the operating point of $1300 \mathrm{lph}$

\begin{tabular}{|c|c|c|c|}
\hline $\begin{array}{c}\text { Error and quality } \\
\text { indices measures }\end{array}$ & $\begin{array}{c}\text { IMC } \\
\text { TUNED } \\
\text { PID }\end{array}$ & $\begin{array}{c}\text { CC } \\
\text { TUNED } \\
\text { PID }\end{array}$ & $\begin{array}{c}\text { ZN } \\
\text { TUNED } \\
\text { PID }\end{array}$ \\
\hline ISE & 0.57 & 0.83 & 0.91 \\
\hline IAE & 0.801 & 0.86 & 0.843 \\
\hline ITAE & 0.41 & 0.58 & 0.68 \\
\hline $\mathrm{t}_{\mathrm{r}}(\mathrm{Sec})$ & 5.34 & 8.921 & 13.973 \\
\hline $\mathrm{t}_{\mathrm{s}}(\mathrm{Sec})$ & 24.137 & 31.856 & 52.965 \\
\hline$\% \mathrm{M}_{\mathrm{p}}$ & 19.357 & 3.954 & 33.045 \\
\hline
\end{tabular}

\subsection{Real-time experimentation of local intelligence on fluid transport system}

The proposed local intelligence using IMC-PID controller design performance is experimentally substantiated in realtime on lab-scale experimental set up of the fluid transport system. The control drawing for the process plant architecture is developed by creating separate control loop blocks of PID controller for flow rate. The resultant tuning values of PID controller using IMC technique which is confirmed through simulation is put on to the established local intelligence tune window using CENTUM CS 3000 R4 as shown in Figure 9. 
Through this control drawing builder option, hardware configuration gets synchronized with the flexibility of software customized application to the process plant in order to provide monitoring and control capabilities through online at a remote location from the process plant.

The process plant is starting to run by enabling the auto mode initiated by the local intelligence, when the fixed operating point for flow rate and its pressure is given in the corresponding monitoring particular field parameters faceplate present in the SCADA front end panel of the fluid transport system.

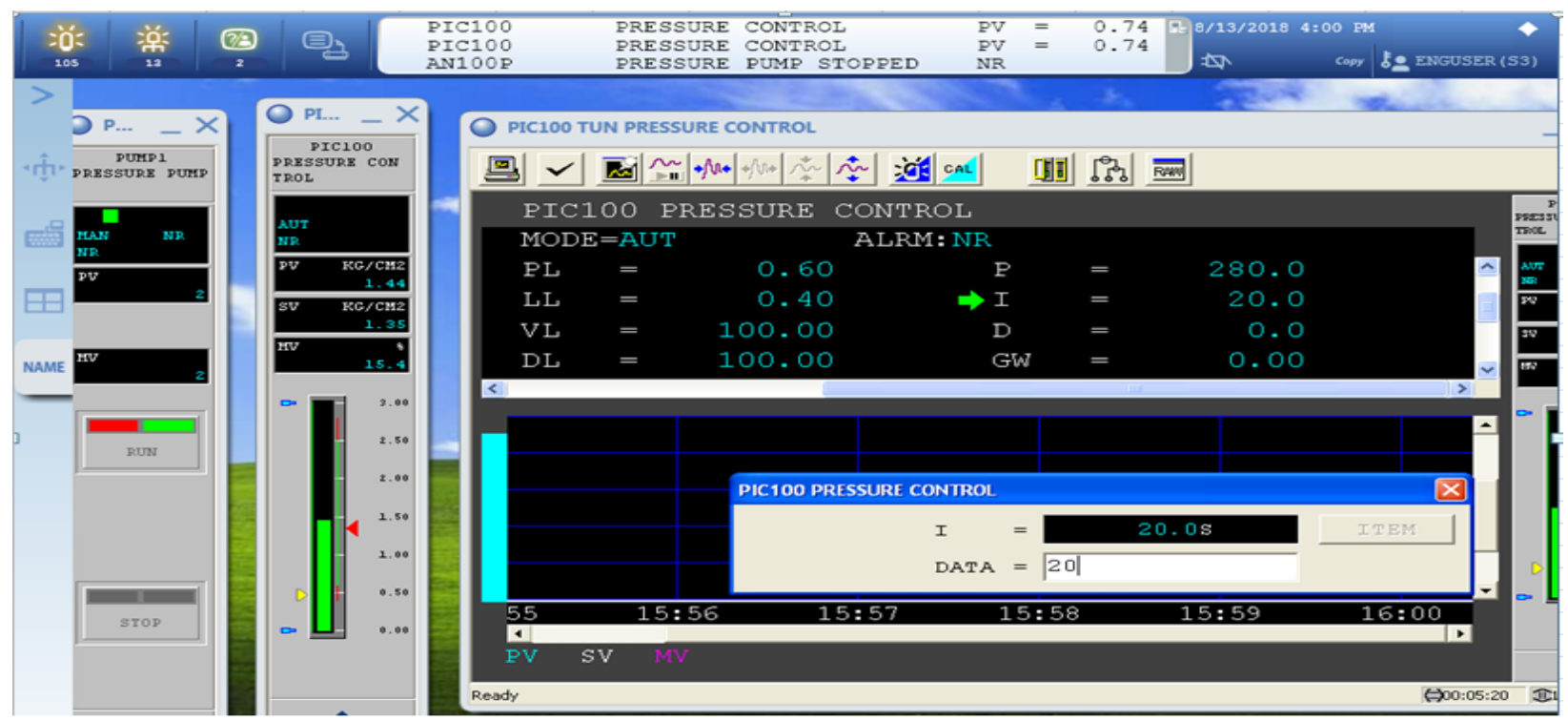

Figure 9. Developed Local intelligence tune window of PID controller for the process plant

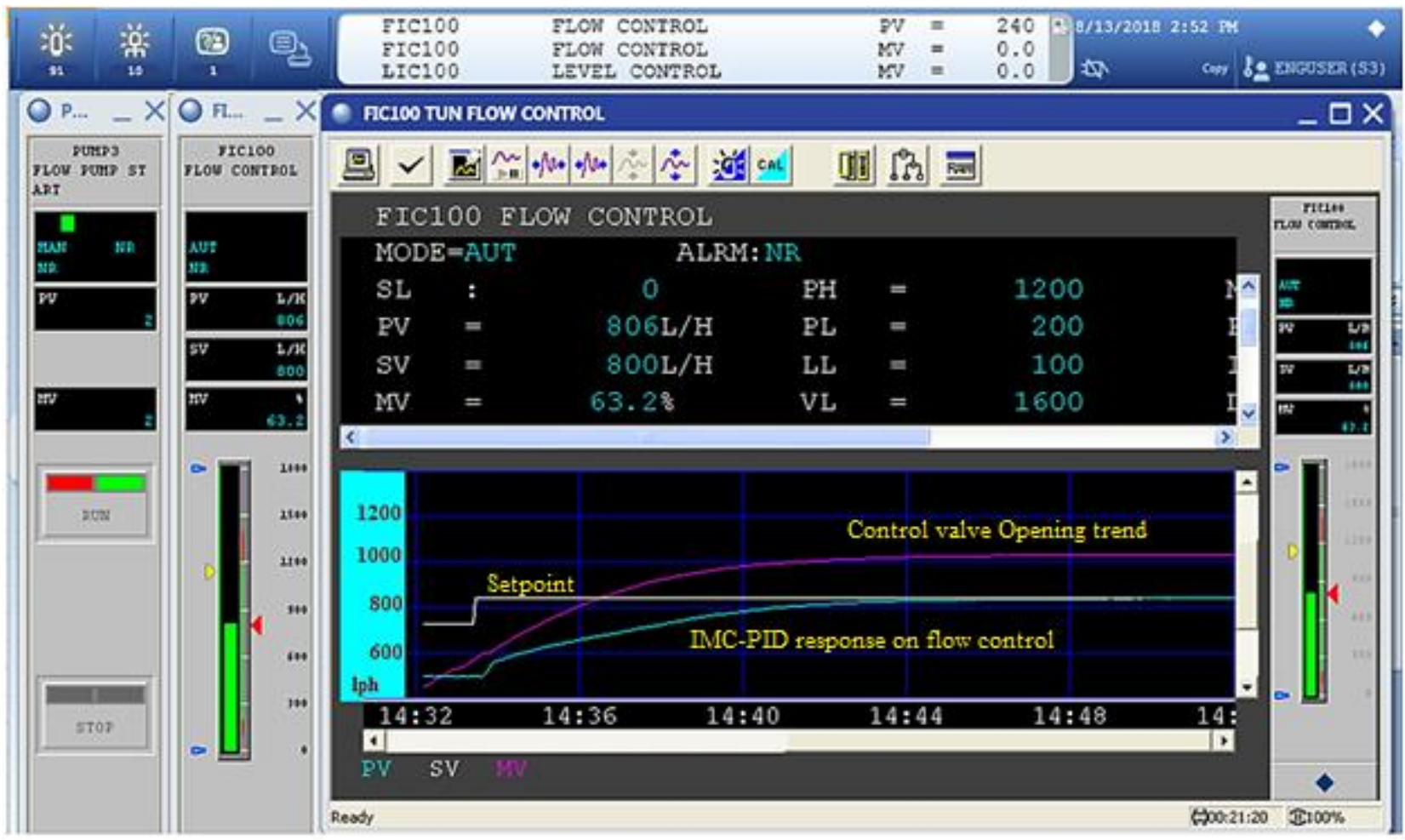

Figure 10. Real-time monitoring and control of Flow rate through Local Intelligence using an IMC-PID controller

The real-time successive data of both pressure and flow rate parameters of the fluid being transported is displayed continuously in Local intelligence trend view window in PIC100.PV/ FIC100.PV tag tab which is present below the trend graph and these data can be exported to excel by exhausting local utility data box option.

Figure 10 reveals the performance of Local intelligence using an IMC-PID controller on remote surveillance and control of flow rate and its pressure on the implemented process plant. The setpoint of flow rate is given as $825 \mathrm{lph}$ respectively. Based on the operating set point, the developed IMC-PID controller running on the back end of the Local intelligence SCADA regulates the operation of control valve opening and closing based on the setpoint of flow rate on the monitoring panel. 


\section{CONCLUSION AND FUTURE SCOPE}

The development and investigation of Local intelligence using an IMC-PID controller on the real-time fluid transport process plant are carried out in this paper. The real-time experimental results show that this Local intelligence using IMC-PID controller acts with provisioning smart decision making on the real-time data of the field parameters in order to optimize the process plant with minimum losses by means of its affordability and the reliability to conduct measurements remotely and in real-time of monitoring and control of field parameters. The experimental validation emphasizes has been engineered to condensed downtime, upgraded system accessibility, enriched control consistency, and unremitting system access. I/O remote-hub module with the control server, operator and engineer stations handling data organization, and gateway utilities are disseminated on an Ethernet linkage to confirm system veracity and well-timed data broadcast communication. The evaluation of this Local intelligence ensures that Condition Based Maintenance with the proactive event-driven computing paradigm for fully exploiting its capabilities by enabling proactive maintenance decisions ahead of time on the process plant, so that the operator can react pre-emptive prior to sort out occurrences of any failure on the process plant.

Regarding the future work, an internet of things (IoT) based reliable monitoring and control with local intelligence using IMC-PID controller modular architecture design along with SCADA/DCS which is outlined in this paper will be implied and investigated on this lab-scale fluid transport system process plant. It is expecting that the proposed IoT architecture will offer a promising and a novel infrastructure to remote monitoring and control in any industrial sectors [13].

\section{CONFLICT OF INTEREST}

All the contributors to this research work have no clashes of attention to announce and broadcasting this article.

\section{ACKNOWLEDGMENT}

This research work is carried out under the Senior Research fellowship received from CSIR (Council for Scientific and Industrial Research) with grant no.678/08(0001)2k18 EMR-I.

\section{REFERENCES}

[1] Galloway, B., Hancke, G.P. (2013). Introduction to industrial control networks. IEEE Communications Surveys \& Tutorials, 15(2): 860.
[2] Kim, M. (2018). A quality model for evaluating IoT applications. International Journal of Computer and Electrical Engineering, 8(1): 66-70. https://doi.org/10.17706/ijcee.2016.8.1.66-76

[3] Liu, X., Liu, H., Wan, Z., Chen, T., Tian, K. (2015). Application and study of the internet of things used in rural water conservancy project. Journal of Computational Methods in Sciences and Engineering 15(3): 477-488. https://doi.org/10.3233/JCM-150560

[4] Meribout, M. (2011). A wireless sensor network based infrastructure for real-time and online pipeline inspection. IEEE Sensor Journal, 1(11): 2966-2972. https://doi.org/10.1109/JSEN.2011.2155054

[5] Shamsuzzoha, M. (2014). A unified approach for proportional-integral-derivative controller design for time delay processes. Korean Journal of Chemical Engineers, 32(4): 583-596. https://doi.org/10.1007/s11814-014-0237-6

[6] Morari, M., Zafiriou, E. (1989). Robust Process Control. NJ: Prentice Hall Englewood Cliffs.

[7] Mohammed, N., Jawhar, N. (2011). A fault tolerant wired/wireless sensor network architecture for monitoring pipeline infrastructures. In 2nd International Conference on Sensor Technologies and Applications, 13: 178-184. https://doi.org/10.1109/SENSORCOMM.2008.116

[8] Priyanka, E.B., Maheswari, C. (2016). Parameter monitoring and control during petrol transportation using PLC based PID controller. Journal of Applied Research and Technology, 14(5): 125-131. https://doi.org/10.1016/j.jart.2016.03.004

[9] Priyanka, E.B., Maheswari, C., Thangavel, S. (2018). Remote monitoring and control of an oil pipeline transportation system using a Fuzzy-PID controller. Flow Measurement and Instrumentation, 62(3): 144-151. https://doi.org/10.1016/j.flowmeasinst.2018.02.010

[10] Seborg, D.E., Edgar, T.F., Mellichamp, D.A. (2004). Process Dynamics and Control. $2^{\text {nd }}$ edition, John Wiley \& Sons, New York, USA.

[11] Priyanka, E.B., Maheswari, C., Thangavel, S. (2018). Remote monitoring and control of LQR-PI controller parameters for an oil pipeline transport system. Proceedings of the Institution of Mechanical Engineers, Part I: Journal of Systems and Control Engineering, pp. 1-12. https://doi.org/10.1177/0959651818803183

[12] Tan, W., Marquez, H., Chen, T. (2010). IMC design for unstable processes with time delays. Journal of Process Control, 13(5): 203-213. https://doi.org/10.1016/S09591524(02)00058-6

[13] Priyanka, E.B., Maheswari, C., Thangavel, S. (2018). IoT based field parameters monitoring and control in press shop assembly. Internet of Things, 3-4: 1-11. https://doi.org/10.1016/j.iot.2018.09.004 